\title{
The Moral Economy of Water: General Principles for Successfully Managing the Commons
}

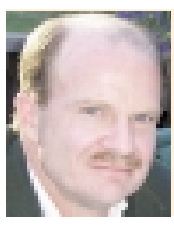

\section{Paul Trawick}

Department of Anthropology

University of Kentucky, Lexington KY 40506-0024 (USA)

E-Mail: pbtraw0@pop.uky.edu

http://www.uky.edu/ArtsSciences/Anthropology/

faculty.htm

\section{XXXXX}

Few works in social science have had as much impact on policy as Garrett Hardin's attempt, in "The Tragedy of the Commons" [1], to explain the tendency of people to overexploit the resources that they hold in common in terms of an irresolvable conflict between the interests of the individual, said to be inherently selfish, and the cooperative needs of the group. The results of such a tragedy are, of course, evident today in many parts of the world in the use of common-property resources. Yet many authors have strongly criticized the theory, based on numerous examples of communities where local people have managed such resources cooperatively, and done so quite effectively, over a very long period of time. This rebuttal has turned attention toward the related task ${ }^{[2-5]}$ of devising an alternative theory to explain how people have been able to overcome their conflict of interest, escape the 'commons dilemma', and pursue the common good.

Progress toward this goal has been especially noteworthy with regard to one vital resource, irrigation water, which is particularly significant given the impending water crisis that threatens nearly every country in the 'developing' world. Recent research, however, lends new support to the effort and promises to thoroughly refute and revise the conventional theory. It indicates that local people in a great many communities in several different parts of the world long ago arrived, independently, at a sustainable solution to the 'commons dilemma', creating a set of principles for sharing scarce water in an equitable and efficient manner that minimizes social conflict. Wherever communities have managed a scarce resource autonomously, and done so effectively over a long period of time, the principles of distribution and use appear in many cases to be highly similar if not exactly the same, and this seems to be true regardless of whether the resource is communally or privately owned.

This finding could have a major impact on the policies of institutions such as the World Bank and the various regional banks with which it is affiliated. Their development programs continue to be strongly shaped by the conventional theory and they now advocate water privatization - along with State ownership and control, one of Hardin's proposed solutions to the commons dilemma - on a massive scale ${ }^{[6]}$. My research indicates that water markets do not work in the manner that they are widely thought to work, at least not in the small-scale systems that typify most of the 'developing world', since it reveals heretofore unrecognized commonalities in the dynamics of successful communal and market systems.

Scholars and scientists have made steady and important progress in critiquing and revising the theory of the tragedy, most notably Ostrom ${ }^{[5,7,8]}$ and Tang ${ }^{[9]}$, who have led the way in identifying, through comparison of a large number of case studies in different countries, basic design principles that all effective locally-run irrigation systems seem to share. Their focus has tended to be on small-scale canal systems of 1000 hectares or less ${ }^{[10]}$, the kind of "indigenous" or peasant community system found throughout much of the globe, since such limited scale, and the kind of intensive face-to-face interaction among water users that this makes possible, seems to be a critical thing that the systems have in common ${ }^{[7 a, d]}$. However, most of the principles identified thus far remain rather abstract, more suitable for predicting the general conditions under which people will be able to come up with a solution than for showing them how, in concrete terms, to manage water effectively in situations where they have failed or lost the ability to do so on their own.

\section{XXXXX}

The effort to revise theory and make policy has been hindered by the limitations of the primary data, which are typically thoroughly etic, that is, objective, scientific, and descriptive at the system level, but without incorporating much of the emic point of view, the more subjective and culture-bound perspective of the water user.

Analysts have also tended to emphasize the diversity that exists among local irrigation systems, while not giving enough attention to the one important feature that nearly all of them do have in common, at least at certain times of the year, and that is water scarcity.

All of this has obscured the fact that the keys to local success in dealing with water scarcity - that is, operational principles which together instill a strong positive incentive in people to obey the rules and conserve the resource, rather than a negative one that merely rests on punishing infractions appear to be highly similar if not exactly the same in many parts of the world. Once the principles are identified ethnographically, and the way that they work together from the water users' point of view is understood, the parallels in other countries become evident and a striking pattern is revealed.

These principles for successful management at the local community level, as identified in several villages in the Peruvian Andes ${ }^{[11]}$ are:

(1) autonomy:

(2) contiguity:

(3) uniformity the community has and controls its own flows of water;

during each distribution cycle, water is given to fields in a fixed contiguous order based on their location along successive canals, starting at one end of the system and moving systematically across it;

- among water rights: for each major 
(4) proportionality (equity)

(5) regularity:

(6) transparency: source or canal flow, everyone receives water with the same frequency;

- in technique: everyone irrigates in the same basic way;

- among rights: no one can use more water than the proportional amount to which the extent of their land entitles them, nor can they legally get it more often than everyone else;

- among duties: people's contributions to maintenance of the canal system must be proportional to the amount of irrigated land that they have;

things are always done in the same way under conditions of scarcity; no exceptions are allowed, and any unauthorized expansion of irrigation is prohibited;

everyone knows the rules and has the capacity to confirm, with their own eyes, whether or not those rules are generally being obeyed, to detect and denounce any violations that occur.

Close examination of the published data suggests that this same basic solution to the problem of scarcity has been worked out independently by peasants and indigenous people in many parts of Peru, as well as Mexico, Spain, India, Nepal, Sri Lanka, and the Philippines ${ }^{[5,7 b, d, 12-21]}$. Although the evidence for this is not entirely conclusive, and requires one to read between the lines of these works, it is compelling enough to show that some of these local irrigation systems badly need a second look ${ }^{[22]}$.

The studies cited above do reveal the existence of some of the principles, in a manner that logically implies, or at least strongly suggests, the presence of others, although they have not been explicitly recognized and discussed. Autonomy, for example, is invariably mentioned, since that is basic to the "indigenous" systems, namely the traditional community-based systems that have been so extensively studied. Another widelynoted principle is proportionality, both among individual water rights (that is, all have the same land-to-water ratio) and between people's rights and their corresponding maintenance duties ${ }^{[5,7-9,13]}$. However, proportionality also implies uniformity, at least in the watering frequency, since without it there can be no real proportionality among people's rights, and a significant degree of uniformity in people's technique of water use as well, or at least some limits on the nature or extent of such use, for the same reason.

It is possible, through this kind of logical inference, to confirm the likelihood that all of the aforementioned principles are present in many of the systems described in the literature. One of the virtues of the comparative analyses that have been done to date, particularly those of Ostrom ${ }^{[5,7,8]}$, and Tang ${ }^{[9]}$, is that they show how widespread the principle of proportionality is, and thereby reveal this possibility ${ }^{[15,17,20,21]}$. The pattern, however, must ultimately be confirmed firsthand through fieldwork if it is to help in the effort to reformulate theory and if it is ever to have an impact on resource management policy. The principles must be shown to be recognized and understood by the water users themselves, and to be motivating their cooperation and minimizing the temptation to cheat or "free-ride".

\section{XXXXX}

The results of my research, both as an ethnographer and as a consultant on water reform for the World Bank, show that a strong motive for conservation will not materialize as a result of privatization and the creation of markets alone, either in the Andean highlands or in other geographically similar parts of the world. The solution to the water crisis does not appear to lie in the "invisible hand" of the market, in the profit motive and the law of supply and demand, at least not in the small-scale systems that typify most parts of the globe. Rather, as I have argued elsewhere ${ }^{[00]}$, it seems to lie in a direct and obvious link, established by the aforementioned principles and clearly recognized by the irrigators themselves, between the efficiency and orderliness of water use and the duration of the irrigation cycle. The logic and effectiveness of the principles does not, I think, in any way depend on water being worth money, although that can be and is a feature of some of the systems where the principles appear to be in place today.

An intriguing example of the latter is the community of Alicante in Spain, the oldest water market in the world and one of the few places where peasants have privatized the resource and adopted that approach to its management ${ }^{[15,00]}$. My own analysis of the published data strongly suggests the same set of basic principles is operating in Alicante as in the neighboring districts of Valencia, Murcia, and Orihuela, and these are the same principles that I encountered in my ethnographic research in Peru. The latter communities are successful systems of communal water management, originally studied by the same authors, which also stand out in the literature as examples of success. Alicante is widely thought by economists to demonstrate the effectiveness of the profit motive in giving farmers an incentive to use the resource efficiently and with minimal conflict. But close inspection reveals that its irrigation system has not been well described nor well understood from the water users' point of view. Nevertheless, it does seem clear that in Alicante, any water that is transferred among users is delivered on the same schedule, and in the same contiguous order, as people's regular water allotments, and it only seems to be available with the same frequency, as part of the general irrigation cycle. Other basic principles, such as proportionality among rights and between rights and duties, appear to exist as well, at least with regard to some of Alicante's private water. The existence of the same basic operating principles in such seemingly different kinds of systems, under property regimes that seem to be diametrically opposed, can only mean that the way the latter systems, in particular, work has been widely misunderstood.

Below is a list of the principles that are either explicitly mentioned or at least well described in the published accounts of Valencia, Murcia-Orihuela, and Alicante, as well as other principles, shown in parentheses, whose existence can be logically inferred from that information.

$\square$ Valencia: proportionality, contiguity, (uniformity, regularity, transparency);

turno system ${ }^{1)}, 7$ irrigation communities.

$\square$ Murcia and Orihuela: proportionality, contiguity (uniformity, regularity, transparency); tanda system ${ }^{1)}, 40$ user communities.

$\checkmark$ Alicante: proportionality (contiguity, uniformity, regularity, transparency);

market system, 1 community.

The presence of such similar or even identical principles in the two settings can only indicate that the monetary incentive to conserve, where it exists, must be of secondary importance. In this general kind of system, by using the resource wisely,

\footnotetext{
1) Please explain turno and tanda!?
} 
obeying the rules and respecting tradition, people are optimizing the frequency of irrigation for themselves and everyone involved, responding to a close correspondence between individual self-interest and the common good that cannot be achieved through any other kind of institutional arrangement.

The fact that people in the market system can sell any surplus water that they choose not to use at a particular time, or can buy more if they wish to in order to alleviate the prevailing scarcity, does not mean that gaining such income is their primary motivation, or even a very strong one, and this point has not been understood.

\section{XXXXX}

A final example worthy of mention are the peasant communities in northern Chile, the only country in the world that has fully privatized its water and the only one that supposedly has a "national" water market. Again, Chile is widely cited by economists as an example of the efficiency of such markets, which are thought to function effectively even in the smallscale canal systems of the Andes and other parts of the socalled Third World.

During work as a World Bank consultant in 1993 through 1995, I was able to find out from Chilean colleagues that, contrary to what Bank publications suggest, there have in fact been no significant sales of water between households within that country's peasant communities since the current water law was implemented in 1981. Instead, the reason for the efficiency of local water management in those cases seems to lie in a process called "regularization", according to which, according to preliminary but highly reliable accounts, the national government either implemented or endorsed practices that manifested the same set of principles previously described ${ }^{[23]}$. This was seen as a necessary first step in regularizing water use and clarifying individual rights in communities that were being integrated into the market system. However, it was often discovered that such use was already quite regular in such cases and that individual rights were often clearly defined, in an equitable way, under customary systems of water use. It seems likely, from what I have been able to learn, that the aforementioned principles already existed locally and are in fact a survival of the much older Andean tradition of water management that I encountered in Peru.

This tradition, which I call "the moral economy of water", rests on the principle of equity, a concept that is often mentioned but has proven notoriously difficult to define, in concrete terms, for most natural resources. In the field of irrigation and water rights, however, the concept seems easy to define and appears to have been widely defined by people in the same way, wherever they have been allowed to do so on their own. It necessarily encompasses both uniformity and proportionality. This hypothesis, if ultimately confirmed through fieldwork in the irrigation systems described above, will be pivotal in the effort to build more powerful theories of collective action, and to devise policies that strongly encourage such action by local communities to take place.

At a time when governments throughout the 'developing' world are having to get out of the business of managing water and tighten their belts financially, under the impact of programs of "structural adjustment", the need for such a new direction for policy is especially great.

If my hypothesis is correct, and the evidence is quite strong that it is, it will indicate that water management is one of the few domains of human life where an optimal and widely applicable solution to a major social problem exists, one based on a moral principle that has been recognized and affirmed by people from widely different cultures and backgrounds, and upon which they seem generally able to agree.

Such a finding, in both communal and market systems, would surely find an important place in the efforts of many scholars and scientists to find ways of creating a more equitable, sustainable, and secure world than the one in which we now live.

\section{References}

[1] G. Hardin: "The Tragedy of the Commons", Science 162 (1968) 1243-1248.

[2] National Research Council (NRC): Proceedings of the Conference on Common Property Management, National Academy Press, Washington DC (1986).

[3] B. McCay, J. Acheson (Ed.): The Question of the Commons: The Culture and Ecology of Communal Resources, University of Arizona Press, Tucson AZ (1987).

[4] D. Bromley (Ed.): Making the Commons Work: Theory, Practice and Policy, Institute for Contemporary Studies, San Francisco CA (1992).

[5] E. Ostrom: Governing the Commons: The Evolution of Institutions for Collective Action, Cambridge University Press, New York (1990).

[6] World Bank: Peru: A User-Based Approach to Water Management and Irrigation Development, Report No. 13642-PE, World Bank, Washington DC (1995).

[7] a) E. Ostrom: "Institutional Arrangements for Resolving the Commons Dilemma", in Ref. [3], p. 250-265;

b) E. Ostrom: Crafting Institutions for Self-Governing Irrigation Systems, Institute for Contemporary Studies Press, San Francisco CA (1992); c) E. Ostrom, R. Gardner: "Coping with Asymmetries in the Commons Self-Governing Irrigation Systems Can Work", Journal of Economic Perspectives 7/4 (1993) 93-112;

d) E. Ostrom: "Reformulating the Commons", in J. Burger, R. Norgaard, E. Ostrom, D. Policansky, B. Goldstein (Ed.): The Commons Revisited: An Americas Perspective, Island Press, Washington DC (1998), p. 1-26.

[8] E. Ostrom, J. Burger, C. Field, R. Norgaard, D. Policansky: "Revisiting the Commons: Local Lesson, Global Challenges", Science 284 (1999) 1-10.

[9] S.Y. Tang: Institutions and Collective Action: Self-governance in Irrigation, ICS Press, San Francisco CA (1992).

[10] J. Mabry, D. Cleveland: "The Relevance of Indigenous Irrigation: A Comparative Analysis of Sustainability", in J. Mabry (Ed.): Canals and Communities: Small-Scale Irrigation Systems, University of Arizona Press, Tucson AZ (1996), p. 227-260.

[11] P. Trawick: "Historia de la Irrigación y Conflictos de Classes en la Sierra", Debate Agrario, No. 18 (1994), p. 21-44;

The Struggle for Water in the Andes: A Study of Technological Change and Social Decline in the Cotahuasi Valley of Peru, Ph.D. Dissertation, Yale University (1994);

"Water Reform and Poverty in the Peruvian Highlands", in M. Thobani (Ed.): Peru: A User-Based Approach to Water Management and Irrigation Development, World Bank Report No. 13642-PE (1995), Annex B, p. 1-20;

"La Privatization del Agua: Alternative Andina para una Nueva Ley de Aguas", QueHacer, Vol. 115 (1998), DESCO, Lima (1998), p. 36-41; "La Nueva Ley de Aguas: Una Alternativa Indigena a Las Reformas Propuestas", Debate Agrario: Analisis y Alternativas, No. 28 (1999), Centro Peruano de Estudios Sociales (CEPES), Lima, p. 85-102; "Successfully Governing the Commons: Principles of Social Organization in an Andean Irrigation System", Human Ecology 29/1 (2001) 1-25 "The Moral Economy of Water: Equity and Antiquity in the Andean Commons", American Anthropologist 103/2 (2001) 361-379; The Struggle for Water in Peru: Comedy and Tragedy in the Andean Commons, Stanford University Press, Palo Alto CA (October 2002); "Against the Privatization of Water: An Indigenous Model for Local Success in Governing the Commons", World Development, in press; "Comedy and Tragedy in the Andean Commons", Journal of Political Ecology, in press.

[12] J. Treacy: Las Chacras de Corporaque: Andeneria y Riego en el Valle del Colca, Instituto de Estudios Peruanos, Lima (1994).

[13] D. Guillet: "Canal Irrigation and the State: The 1969 Water Law and Irrigation Systems in the Colca Valley of Southern Peru", in W.P. Mitchell, D. Guillet (Ed.): Irrigation at High Altitudes: The Social Organization of Water Control Systems in the Andes, Society for Latin American Anthropology Publication Series, Vol. 12 AAS, Washington DC (1994), p. 167-188.

[14] R. Hunt, E. Hunt: "Canal Irrigation and Local Social Organization", 
Current Anthropology 17 (1976) 129-157.

[15] A. Maass, R.L. Anderson: And the Desert Shall Rejoice: Conflict, Growth and Justice in Arid Environments, MIT Press, Cambridge MA (1978).

[16] E. W. Coward: "Principles of Social Organization in an Indigenous Irrigation System", Human Organization 38/1 (1979) 28-36.

[17] R. Wade: "Common Property Resource Management in South Indian Villages", in Ref. [2], p. 231-258;

Village Republics: Economic Conditions for Collective Action in South India, Cambridge University Press, Cambridge (1988).

[18] R. de los Reyes: 47 Communal Gravity Systems: Organizational Profiles, Ateneo de Manila University, Institute of Philippine Culture, Quezon City, Philippines (1982).

[19] R.Y. Siy: Community Resource Management: Lessons from the Zanjera, University of the Philippines Press, Quezon City (1982).

[20] N. Sengupta: Managing Common Property: Irrigation in India and the Philippines, Sage Press, New Delhi (1991).

[21] W.F. Lam: Governing Irrigation Systems in Nepal: Institutions, Infrastructure, and Collective Action, ICS Press, Oakland CA (1998).

[22] P. Trawick: "The Moral Economy of Water: The Andean Commons as a Clear Stream of Thought", unpublished manuscript, to be submitted to Advances in Global Change Research.

[23] A. Dourojeanni, A. Jouravlev: "El Codigo de Agues de Chile: Entre la Ideologia y la Realidad", Debate Agrario, No. 29-30 (1999), CEPES, Lima, p. 138-185. 